\title{
Lysolecithin: A factor in the pathogenesis of gastric ulceration?'
}

\author{
A. G. JOHNSON AND SUSAN J. MCDERMOTT \\ From the Department of Surgery, Charing Cross Hospital Medical School, London
}

SUMMARY Lysolecithin is formed when pancreatic juice and bile mix in the duodenum. Lysolecithin concentrations have been measured in intermittent samples of night gastric juice from patients with gastric ulcers and duodenal ulcers and in normal controls. In gastric ulcer patients, the mean of the peak concentrations $(444 \mu \mathrm{g} / \mathrm{ml})$ and mean of concentrations in all samples $(199 \mu \mathrm{g} / \mathrm{ml})$ were significantly higher than in controls $(34 \mu \mathrm{g} / \mathrm{ml}$ and $18 \mu \mathrm{g} / \mathrm{ml}$ respectively). Duodenal ulcer patients had normal or moderately raised values. The levels in gastric ulcer patients were as high as those which have been found experimentally to cause severe damage to the gastric mucosal barrier, and it is concluded that lysolecithin may be as important, or more important, than bile salts in the destruction of the gastric mucosal barrier and therefore in the aetiology of gastric ulcer.

The concept of a role for the regurgitation of duodenal juice in the aetiology of gastric ulceration is assuming increasing importance. A number of workers (Du Plessis, 1965; Capper, 1967; Rhodes, Barnardo, Phillips, Rovelstad, and Hofman, 1969) have found higher concentrations of bile salts in the gastric juice of patients with gastric ulcer than in normal controls and it has been suggested that the bile salts damage the gastric mucosal barrier. Janowitz (1969), however, has pointed out the possible importance of studying other substances in the duodenal juice, and Davenport (1970) has found that the phospholipid, lysolecithin, causes a marked increase of sodium ion flux across the gastric mucosal barrier of the canine Heidenhain pouch.

The purpose of the present study is to determine whether, in the human subject, lysolecithin occurs in sufficient concentration in the night gastric juice to cause mucosal damage.

\section{Metabolism of Lysolecithin}

Lysolecithin is highly toxic to cell membranes (Gottfried and Rapport, 1963) and like bile salts is a strong detergent. It is formed in the duodenum when the phospholipase A of pancreatic juice hydrolyses the lecithin in bile. This reaction is activated by bile acids and trypsin. Lysolecithin may be further

${ }^{1}$ This paper is based on communications to the British Society of Gastroenterology and the Surgical Research Society.

Received for publication 29 November 1973. hydrolysed to glyceryl phosphorylcholine by phospholipase $\mathrm{B}$, but this reaction is inhibited by bile acids. Figure 1 summarizes the metabolic pathway.

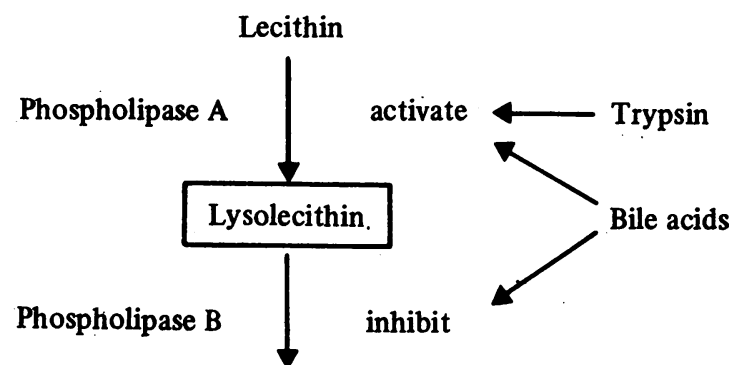

Glycerylphosphorylcholine and fatty acid

Fig 1 Metabolic pathway

\section{Subjects and Methods}

Twenty-five patients were studied from three clinical groups: (1) controls, symptomless volunteers or patients with a normal barium meal and gastroscopy, five patients (all male); (2) gastric ulcer, those with active type I curve gastric ulcers, 10 patients (seven males, three females); (3) duodenal ulcer, those with active duodenal ulcers, 10 patients (eight males, two females). 
The patients were given the standard hospital supper at $6 \mathrm{pm}$. A nasogastric tube was passed at $9.30 \mathrm{pm}$, the position checked using the nonfluoroscopic method of Hassan and Hobsley (1968), and the tube secured in position. Ten millilitre samples were aspirated throughout the night at $10 \mathrm{pm}, 12$ midnight, $2 \mathrm{am}, 4 \mathrm{am}$, and $6 \mathrm{am}$ and placed in tubes containing $2 \mathrm{mM}$ EDTA and $5 \mathrm{mM}$ $\mathrm{Ca} \mathrm{Cl}_{2}$ to inhibit phospholipase A activity (Magee, Gallai-Hatchard, Sanders, and Thompson, 1962) and deep frozen while awaiting analysis. The position of the tube was further checked after the last sample to ensure that it had not moved during the study.

\section{ESTIMATION OF LYSOLECITHIN}

Total lipid phosphorus was measured by the method of Gomori (1942). Lecithin and lysolecithin were separated using silicic acid column chromatography (Borgström, 1957), lecithin being eluted with $30 \%$ of $95 \%$ ethanol in chloroform and lysolecithin with $50 \mathrm{ml}$ of methanol. Standards were obtained from Koch-Light Laboratories Ltd, and recovery from the columns averaged $90 \%$. The purity of the lysolecithin fraction was confirmed by thin-layer chromatography (Skipski, Peterson, and Barclay, 1964). The peak lysolecithin value is defined as the highest concentration reached at any time during an individual test and the results are expressed as (a) the mean of the peak values of all tests in a group and (b) the mean of all the values of all tests in a group.

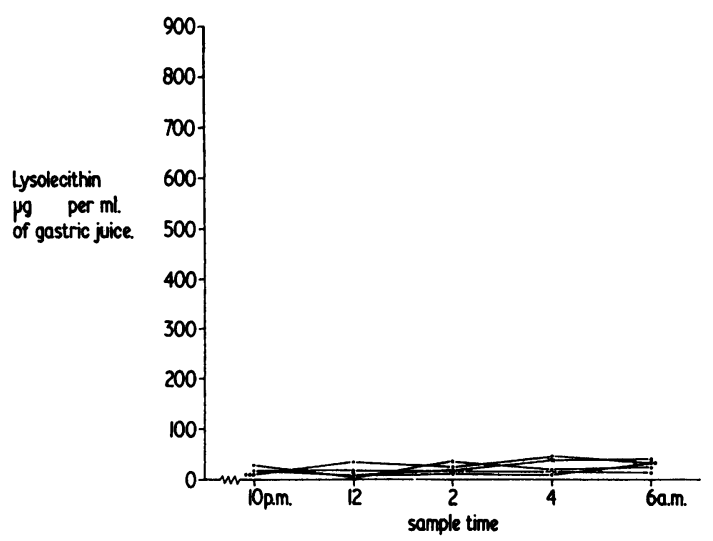

Fig 2 Lysolecithin concentrations in samples of gastric juice from normal control patients

\section{Results}

The results are shown in figures 2 to 4 . The consistently low values in the control group and the high but variable levels in the gastric ulcer group are evident. The duodenal ulcer patients had values intermediate between the other two groups but nearer those of the controls.

There was a highly significant difference in both the mean of the peak values $(P<0.05)$ and mean of all values $(P<0.001)$ between the gastric ulcer and

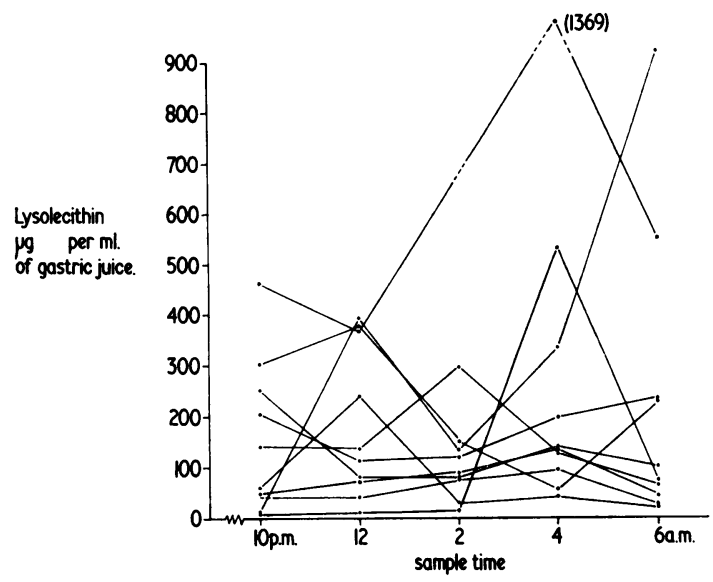

Fig 3 Lysolecithin concentrations in samples of gastric juice from patients with gastric ulcer

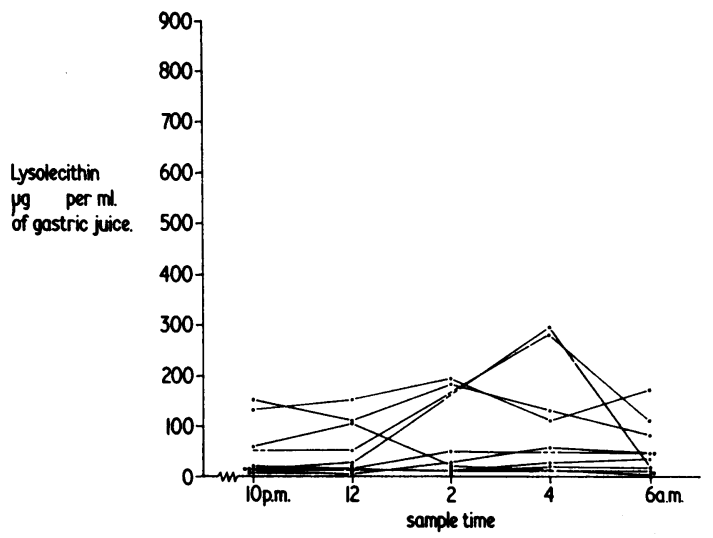

Fig 4 Lysolecithin concentrations in samples of gastric juice from patients with duodenal ulcer

control groups. The duodenal ulcer patients differed significantly from both other groups for the mean value of all samples $(P<0.005)$ but the peak values were not significantly different from those of the controls (P > 0.05). Tables I and II give the details with the probability values for the difference between the groups (using Student's $t$ test and its modification for small samples). 


\begin{tabular}{lcl}
\hline Group & $\begin{array}{l}\text { Lysolecithin Values } \\
(\mu g / m l)\end{array}$ & $\begin{array}{l}\text { Significance of } \\
\text { Difference }\end{array}$ \\
\hline Control & $34(5)^{1}$ & $\begin{array}{l}\text { Control v GU } \\
(\mathrm{P}<0.05)\end{array}$ \\
Gastric ulcer (GU) & $444(10)$ & $\begin{array}{l}\text { GU v DU } \\
(\mathrm{P}<0.05)\end{array}$ \\
Duodenal ulcer (DU) & $122(10)$ & $\begin{array}{l}\text { Control v DU } \\
(\mathrm{P}>0.05)\end{array}$ \\
\hline
\end{tabular}

Table I Mean of peak values of lysolecithin from each clinical group

${ }^{1}$ Number of samples in parentheses.

\begin{tabular}{lcl}
\hline Group & $\begin{array}{l}\text { Lysolecithin Values } \\
(\mu \mathrm{gg} / \mathrm{ml})\end{array}$ & $\begin{array}{l}\text { Significance of } \\
\text { Difference }\end{array}$ \\
\hline Control & $18(23)^{1}$ & $\begin{array}{l}\text { Control v GU } \\
(\mathrm{P}<0.001)\end{array}$ \\
Gastric ulcer (GU) & $199(48)$ & $\begin{array}{l}\text { GU v DU } \\
(\mathrm{P}<0.005)\end{array}$ \\
Duodenal ulcer (DU) & $63(43)$ & $\begin{array}{l}\text { Control v DU } \\
(\mathrm{P}<0.005)\end{array}$ \\
\hline
\end{tabular}

Table II Mean values of lysolecithin in all samples from each clinical group

${ }^{1}$ Number of samples in parentheses.

\section{CONTROL GROUPS}

These were either volunteers with no symptoms of gastrointestinal disease or patients who had been thoroughly investigated for non-ulcer-type upper abdominal pain in whom all investigations of the stomach, duodenum, and gallbladder were normal.

They were not age-matched. It was difficult to obtain informed consent from symptomless subjects to have a nasogastric tube in place all night which accounts for the smaller number in the group. However, the lysolecithin levels are so consistently low that statistically this number is significant.

\section{DUODENAL ULCER GROUP}

This appeared to consist of two populations: five patients with peak values less than $100 \mu \mathrm{g} / \mathrm{ml}$ and five patients with peak values above this level. Statistically they differed from each other for both peak values $(P<0.005)$ and values of all samples (P $<0.001$ ). The subgroup with peak values less than $100 \mu \mathrm{g} / \mathrm{ml}$ (mean of peak samples $37.5 \mu \mathrm{g} / \mathrm{ml}$, mean of all samples $20 \mu \mathrm{g} / \mathrm{ml}$ ) was similar to the control group (P > 0.90) (table III). The subgroup with peak values greater than $100 \mu \mathrm{g} / \mathrm{ml}$ was similar to the gastric ulcer group for the peak values and the mean values of all samples $(P>0 \cdot 10)$. There are probably then two populations in the duodenal ulcer group, one with values similar to those of the controls and the other with values approaching those of the gastric ulcer patients.

\begin{tabular}{lcl}
\hline Subgroup & $\begin{array}{l}\text { Mean of Peak } \\
\text { Values }\end{array}$ & $\begin{array}{l}\text { Mean of All } \\
\text { Samples }\end{array}$ \\
\hline I (peak value $<100)$ & $33(5)^{1}$ & $17(22)$ \\
II (peak value $>100)$ & $171(5)$ & $99(21)$ \\
\hline
\end{tabular}

Table III Mean values of lysolecithin in duodenal ulcer patients

${ }^{1}$ Number of samples in parentheses.

RECURRENT GASTRIC ULCERS AFTER SURGERY Four patients were studied with recurrent gastric ulcers after surgery which destroyed the pylorusone after a Billroth I partial gastrectomy, two after a Polya partial gastrectomy, and one after a pyloroplasty. The mean of all lysolecithin concentrations was $320 \mu \mathrm{g} / \mathrm{ml}$ and the mean of peak values $501 \mu \mathrm{g} / \mathrm{mg}$. These results are higher than those found in primary gastric ulcer.

\section{REPRODUCIBILITY}

Two patients had the test repeated after six months. One patient from the control group had similar results on the two occasions, the peak values being $45 \mu \mathrm{g} / \mathrm{ml}$ and $46 \mu \mathrm{g} / \mathrm{ml}$ and the mean values $28 \mu \mathrm{g} / \mathrm{ml}$ and $35 \mu \mathrm{g} / \mathrm{ml}$. One patient from the gastric ulcer group had a repeat test on readmission with recurrence of the ulcer: both tests showed high levels of lysolecithin with peak values of $430 \mu \mathrm{g} / \mathrm{ml}$ and $920 \mu \mathrm{g} / \mathrm{ml}$ and mean values of $290 \mu \mathrm{g} / \mathrm{ml}$ and $359 \mu \mathrm{g} / \mathrm{ml}$.

\section{LYSOLECITHIN/LECITHIN RATIO}

There was considerable variation in the proportion of lysolecithin to lecithin in different samples even in the same subject. The mean lecithin concentration in the peak samples from the gastric ulcer patients was $278 \mu \mathrm{g} / \mathrm{ml}$ while the mean lysolecithin concentration was $444 \mu \mathrm{g} / \mathrm{ml}$. This means that about $60 \%$ of the lecithin had been hydrolysed to lysolecithin.

\section{THE PH OF THE GASTRIC JUICE}

The samples containing high concentrations of lysolecithin generally had a pH range between 5 and 7 and were obviously bile stained, but significant amounts of lysolecithin were recovered from gastric juice with a $\mathrm{pH}$ as low as $2 \cdot 4$ The combined effect of lysolecithin and acid on the gastric mucosa is more damaging than that of lysolecithin alone

\section{Discussion}

It is clear from these results that gastric ulcer patients have a significantly higher concentration of lysolecithin $(199 \mu \mathrm{g} / \mathrm{ml})$ in their night gastric juice than normal controls $(18 \mu \mathrm{g} / \mathrm{ml})$. The duodenal ulcer 
patients had mean values between the gastric ulcer and control groups. Du Plessis (1965), when measuring bile acid conjugates in early morning gastric samples, similarly found high levels in gastric ulcer patients, low levels in normal subjects, and intermediate levels in those with duodenal ulceration.

Davenport (1970) in his experiments with canine gastric pouches found that the sodium ion flux across the mucosa started to increase when the lysolecithin concentration rose above $100 \mu \mathrm{g} / \mathrm{ml}$. All patients in the control group and half of those in the duodenal ulcer group had concentrations below this level in all their samples, whereas the mean of all samples from gastric ulcer patients was well above this level. It will be interesting to see whether those duodenal ulcer patients with peak levels above $100 \mu \mathrm{g} / \mathrm{ml}$ will develop gastritis or gastric ulcer in the future, secondary to duodenal scarring.

\section{THE RELATIVE IMPORTANCE OF BILE SALTS AND LYSOLECITHIN}

The possible importance of lysolecithin, which is produced when bile and pancreatic juice mix, in damaging the gastric mucosa is supported by Lawson's (1964) finding that a combination of bile and pancreatic juice was more damaging to the canine gastric mucosa than either alone.

Davenport (1970) made the interesting observation that human pancreatic juice alone had no effect on the dog's gastric mucosal barrier. When $5 \mathrm{mM}$ synthetic taurocholate-a concentration equivalent to the mean maximum levels found in the gastric juice of gastric ulcer patients after meals (Rhodes $\boldsymbol{e t}$ al, 1969) - there was still no effect. Lysolecithin, on the other hand, which is not produced when bile salts and pancreatic juice mix, caused considerable damage to the dog's mucosal barrier, when given in a concentration equivalent to the mean of the peak concentrations found in the present gastric ulcer patients. Although bile salts in much higher con- centrations than $5 \mathrm{mM}$ will damage the mucosa (Davenport, 1968) it may be that, clinically, reflux of lysolecithin is as important, or more important, than reflux of bile salts in breaking the mucosal barrier. Once diffusion of hydrogen ions deep into the mucosa can occur, the way is open for further damage leading to gastritis and gastric ulcer.

We are indebted to Mr R. Kumar for his technical assistance, to Miss J. Willoughby for the illustrations, and to Sister H. Preinfalk and the nursing staff of the hospital for their cooperation. A grant from the Charing Cross Hospital Clinical Research Committee is gratefully acknowledged.

\section{References}

Borgström, B. (1957). Studies of the phospholipids of human bile and small intestinal content. Acta chem. scand., 11, 749.

Capper, W. M. (1967). Factors in the pathogenesis of gastric ulcer, Ann. roy. Coll. Surg. Engl., 40, 21-35.

Davenport, H. W. (1968). Destruction of the gastric mucosal barrier by detergents and urea. Gastroenterology, 54, 175-181.

Davenport, H. W. (1970). Effect of lysolecithin, digitonin and phospholipase A upon the dog's gastric mucosal barrier. Gastroenterology, 59, 505-509.

Du Plessis, D. J. (1965). Pathogenesis of gastric ulceration. Lancet, 1, 974-978.

Gomori, G. (1942). A modification of the colorimetric phosphorus determination for use with the photoelectric colorimeter. $J$. Lab. clin. Med., 27, 955-960.

Gottfried, E. L., and Rapport, M. M. (1963). The biochemistry of plasmalogens: 2. Haemolytic activity of some plasmalogen derivatives. J. Lipid Res., 4, 57-62.

Hassan, M. A., and Hobsley, M. (1970). Positioning of subject and of nasogastric tube during a gastric secretion study. Brit. med. J., 1, 458-460.

Janowitz, H. D. (1969). Bile in the stomach. Gastroenterology, 57, 356-357.

Lawson, H. H. (1964). Effect of duodenal contents on the gastric mucosa under experimental conditions. Lancet, 1, 469-472.

Magee, W. L., Gallai-Hatchard, J., Sanders, H., and Thompson, R. H. S. (1962). The purification and properties of phospholipase A from human pancreas. Biochem. J., 83, 17-25.

Rhodes, J., Barnardo, D. E., Phillips, S. F., Rovelstad, R. A., and Hofmann, A. F. (1969). Increased reflux of bile into the stomach in patients with gastric ulcer. Gastroenterology, 57, 241-252.

Skipski, V. P., Peterson, R. F., and Barclay, M. (1964). Quantitative analysis of phospholipids by thin-layer chromatography. Biochem. J., 90, 374-377. 